\title{
Reactive power management by using STATCOM device
}

\author{
Sachin K. Suryvanshee ${ }^{1}$, Shirish V. Sontakke ${ }^{2}$, Atul S. Nikhade ${ }^{3}$, Snusha R. Dharmik ${ }^{4}$, Diwakar T. Korsane ${ }^{5}$ \\ Head of Dept, Electrical Engineering Department, Gurunanak College of Engineering, Nagpur (M.H.), India ${ }^{1}$ \\ Assist. Professor, Electrical Engineering Department, Gurunanak College of Engineering, Nagpur (M.H.), India ${ }^{2,3}$ \\ Lecturer, Electrical Engineering Department, Priyadarshini Polytechnic, Nagpur (M.H.), India ${ }^{4}$
}

Assist. Professor, Electrical Engineering Department, K.D.K.College of Engineering, Nagpur (M.H.), India ${ }^{5}$

\begin{abstract}
As the power system is operated closer to the security limit, environmental constraints restrict the expansion of transmission network. The need for long distance power transmission has increased and little number of operators are engaged in the supervision and operation of power system. Voltage stability has become major problems in many power systems. Due to change in load and the drop in the load, voltage increased and demand for the reactive power increased. This change leads to a progressive \& rapid change of voltage at that location, which may have a cascading effect on neighboring regions that causes voltage drop. In this paper, Static synchronous compensator (STATCOM) is used to maintain the voltage within the limits. STATCOM will manage the reactive power or extract the reactive power.
\end{abstract}

Keywords: FACTS, STATCOM, Voltage Stability, Reactive power.

\section{INTRODUCTION}

Power systems have to be planned, projected, constructed, commissioned and operated in such a way to enable a safe, reliable and economic supply of the load. As power system demand growth increased gradually, while the expansion of power generating stations and transmission lines are limited due to the limited resources and environmental aspects. Therefore, some of the transmission lines get overloaded and introduce new problems with related to voltage profile, power system stability, power flow.

Flexible AC Transmission Systems (FACTS) have all the capability that grid operators need to meet the challenges presented by the fast-changing energy market. It is a new technology using power electronics for controlling the parameters and structures of power systems to optimize the transmission flow, reduce energy losses, and increase the transient/dynamic stability of the system. The term FACTS covers all of the power electronics based systems used in AC power transmission. The main systems are Static Var Compensator (SVC), Thyristor-Controlled Series Capacitor (TCSC), Synchronous Static Compensator (STATCOM), Synchronous Static Series Compensator (SSSC) and Unified Power Flow Controller (UPFC). These devices are designed to remove the power flow limitations such as: stability, thermal, voltage limits and loop flows and meet operator's goals without having to undertake major system additions, i.e. new transmission line construction.

\section{VOLTAGE STABILITY}

Voltage stability is problem in power system which is heavily loaded, faulted, or has shortage of reactive power. The nature of voltage stability can be analyzed by examining the production, transmission and consumption of reactive power. The problem of voltage stability concerns the whole power system although it usually has large involvement in one critical area of the power system.

\section{A. DEFINITION AND TYPES OF VOLTAGE STABILITY}

Voltage stability defined that ability of a power system to maintain steady voltages at all buses in the system after being subjected to a disturbance from a given initial operating condition. It depends on to maintain/restore equilibrium between load demand and load supply from the power system. Instability may cause due to a progressive fall or rise of voltages of some buses.This result in loss of load in an area, or tripping of transmission lines and other elements by their protections leading to cascading outages that in turn may lead to loss of synchronism of some generators.

Large-disturbance voltage stability defined that ability to maintain steady voltages following large disturbances such as system faults, loss of generation, or circuit contingencies. This ability is determined by the system and load characteristics, and the interactions of both continuous and discrete controls and protections.. The study period of interest may extend from a few seconds to tens of minutes.

Small-disturbance voltage stability defined that ability to maintain steady voltages when subjected to small perturbations such as incremental changes in system load. This ability is determined by the characteristics of loads, continuous controls, and discrete controls at a given instant of time.

Short-term voltage stability refers to the dynamics of fast acting load components such as induction motors, electronically controlled loads and HVDC converters. The study period of interest is in the order of several seconds, and analysis requires solution of appropriate system differential equations; this is similar to analysis of rotor angle stability.

Long-term voltage stability refers to slower acting equipment such as tap-changing transformers, thermostatically controlled loads and generator current 
limiters. The operating period may extend to several or line then the series FACTS controller used. FACTS are many minutes, and long-term simulations are required for defined as follows:

analysis of system dynamic performance.

\section{REQUIREMENT OF REACTIVE POWER COMPENSATION}

Except in some situations, power is generated, transmitted, distributed, and utilized as alternating current (AC). However, alternating current has some disadvantages. One is the necessity of reactive power that needs to be supplied along with active power. Reactive power can be leading or lagging. While it is the active power that contributes to the energy consumed, or transmitted, reactive power does not contribute to the energy. Reactive power is an inherent part of the "total power."

Reactive power is either generated or consumed during generation, transmission, and distribution of power to the loads. The impedance of a branch of a circuit in an AC system consists of two components, resistance and reactance. Reactance can be either inductive or capacitive, which contribute to reactive power in the circuit. Most of the loads are inductive, and must be supplied with lagging reactive power. It is economical to supply this reactive power closer to the load in the distribution system.

Hence it is necessary to compensate reactive power in transmission line.

\section{A. FERRANTI EFFECT}

The Ferranti Effect means rise in voltage occurring at the receiving end of a long transmission line, in spite of change in voltage at the sending end, which occurs when may occurs the line is charged but there is a very light load or the load is disconnected. This effect is due to the voltage drop across the line inductance due to charging current in phase with the sending end voltages. Therefore both capacitance and inductance are responsible for producing this phenomenon. The Ferranti Effect will be more for longer line and for higher voltage applied. The relative voltage rise is proportional to the square of the line length. Ferranti effect is also overcome by using facts devices technique.

\section{B. NEED OF REACTIVE POWER}

It is required to maintain the voltage to deliver active power (watts) through transmission lines. If there is not sufficient reactive power, the voltage drops and it is not possible to supply the power demanded by loads through the lines.

It constitutes voltage and current loading of circuits but does not result in active power consumption and hence it is an important component in all ac power transmission. Electromagnetic devices draw lagging currents, producing positive values of reactive power therefore; they are frequently referred to as the absorbers of reactive power. But electrostatic device store electric energy in electric field. These devices draw increased currents and produces negative value of reactive power; thus they are suppliers of reactive power.

\section{FACTS CONTROLLERS}

It is also used for the power flow injects a series voltage. It is possible to prevent overloading on $\mathrm{AC}$ lines under the emergency condition such as in case of loss of a parallel
Flexible AC Transmission System (FACTS): Flexible alternating current transmission systems is the technology for used the improving the power transmission capability by loading transmission lines to its high capacity. It is power electronic-based and other static controllers to enhance controllability and increase power transfer capability in long transmission lines.

\section{A. TYPES OF FACTS CONTROLLERS}

Series connected Controllers.

Shunt connected Controllers.

Combined series-series connected controllers.

Combined series-shunt connected controllers.

\section{B. SHUNT CONTROLLERS}

Static Synchronous Compensator (STATCOM).

Static Synchronous Generator (SSG).

Battery Energy Storage System (BESS).

Superconducting Magnetic Energy Storage

\section{(SMES)}

5. Static Var Compensator (SVC).

Thyristor Controlled Reactor (TCR).

Thyristor Switched Reactor (TSR).

Thyristor Switched Capacitor (TSC).

Static Var Generator or Absorber (SVG).

Thyristor Controlled Braking Resistor (TCBR).

\section{SERIES CONTROLLERS}

Static Synchronous Series Compensator (SSSC). Interline Power Flow Controller (IPFC).

Thyristor Controlled Series Capacitor (TCSC).

Thyristor-Switched Series Capacitor (TSSC).

Thyristor-Controlled Series Reactor (TCSR).

Thyristor-Switched Series Reactor (TSSR).

D. COMBINED SERIES - SHUNT CONTROLLER

Unified Power Flow Controller (UPFC).

Thyristor-Controlled Phase Shifting Transformer TCPST)

3. Interphase Power Controllable (IPC).

\section{STATCOM}

\section{A. OPERATING PRINCIPLES OF STATCOM}

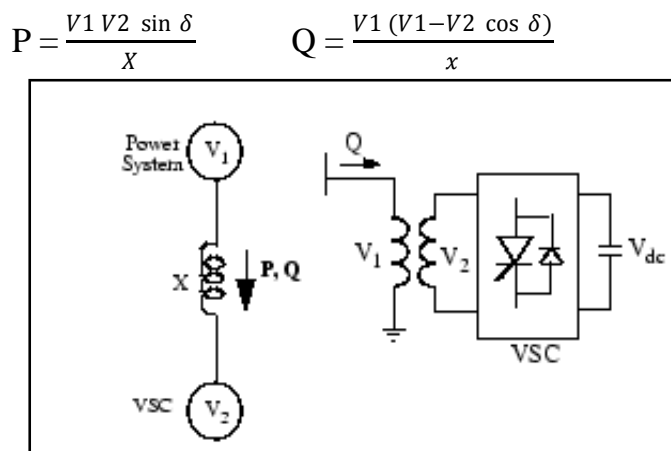

Fig. 1 Operating Principles of STATCOM operation

Where,

V1:- line to line voltage of source $\mathrm{v} 1$

V2:- line to line voltage v2

$X:-$ reactance of interconnection transformer \& filters

$\delta$ : - angle of V1 with respect to V2 
- In steady state operation, the voltage V2 produced by the Voltage source converter is in phase with $\mathrm{V} 1(\delta=0)$, Therefore only reactive power is flowing $(\mathrm{P}=0)$.

- If V2 is less than V1, Reactive power is flowing from V1 to V2 (STATCOM is consuming reactive power).

- $\quad$ On the reverse, if V2 is greater V1, Reactive power is flowing from V2 to V1 (STATCOM is producing reactive power).

The amount of reactive power is given by,

$$
\mathrm{Q}=\frac{V 1(V 1-V 2)}{x}
$$

\section{B. WORKING OF STATCOM}

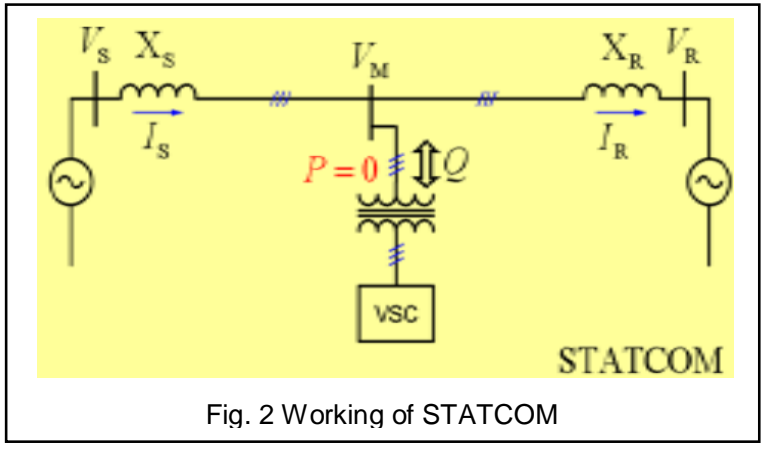

An inverter converts DC current into AC current

- It injects AC current into the network, under the control condition.

- $\quad$ STATCOM produces a co-ordinate AC output by controlling firing angle of triggering gates of inventor.

- It forms a sequence between the 3 phases \& generates a sine waveform approximately.

- It synchronizes the frequency of this generated sine waveform correctly with frequency of network.

- It ensures that the phase sequence coincides.

- It places the applied voltage sine voltage at predetermined point on the voltage wave on network with reference to voltage zero of latter.

- $\quad$ STATCOM applied reactive power into circuit.

- It applied current at 90 Degree to voltage waveform.

- It then passes inductive KVAR or capacitive KVAR into network.

- If generated voltage at STATOM connection is greater than that of network. It transfers capacitive current in network. When capacitive current is lower, it pass inductive current.

- Reactive power requires very less active power because it has no active components'.

- It may seen that it can transfer as many power as the current \& voltage rating of the invertors passes, subject to less time overloads.

- The network of the inverter compares input voltage signal from network with reference point $\&$ adjust the reactive power of STATCOM accordingly.

- The control can be depends on other parameters of the network also such as its KVAR situation, power factor position, etc.

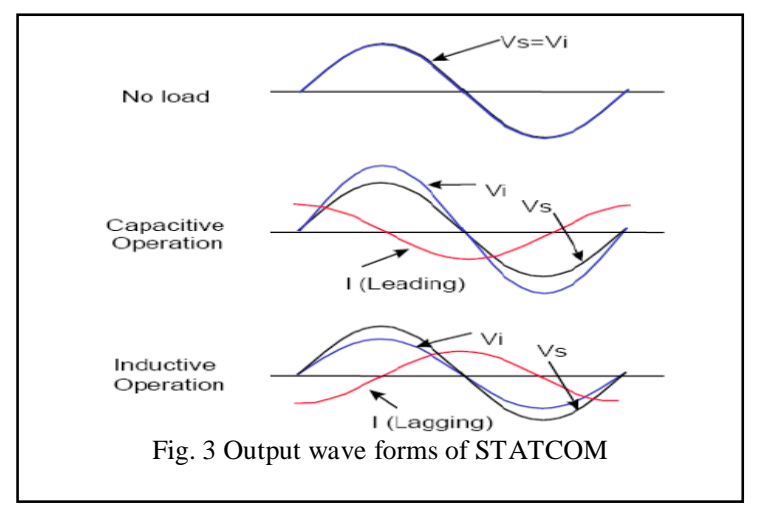

There can be a less active power transfer between the STATCOM and the EPS. The transfer between the inverter and the $\mathrm{AC}$ system can be controlled adjusting the firing angle of the output voltage form the inverter to the voltage angle of the $\mathrm{AC}$ system. This means that the inverter cannot transfer active power to the $\mathrm{AC}$ system from the DC stored energy if the output voltage of the inverter goes before the voltage of the AC system. Also the inverter can consumes the active power of the $\mathrm{AC}$ system if its voltage is delayed in respect to the AC system voltage.

\section{A. MATLAB MODELWITHOUT STATCOM}

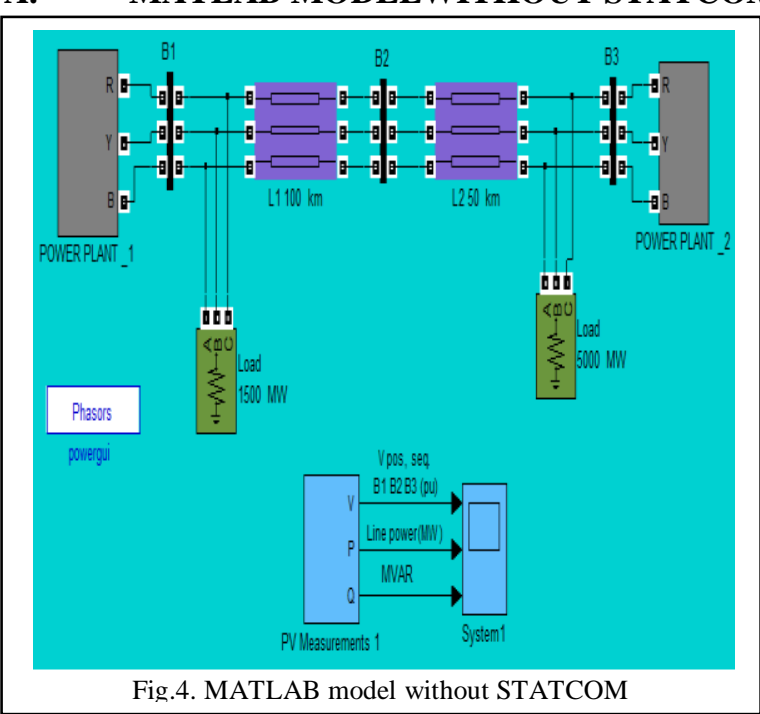

B. MATLAB MODELWITH STATCOM

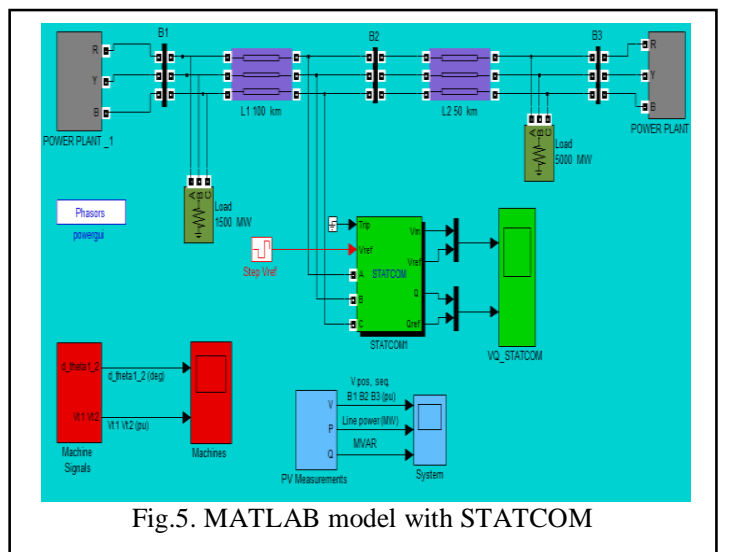


INTERNATIONAL JOURNAL OF INNOVATIVE RESEARCH IN ELECTRICAL, ELECTRONICS, INSTRUMENTATION AND CONTROL ENGINEERING Vol. 2, Issue 12, December 2014

VII. WAVEFORMS OF STATCOM MODEL

A. WAVEFORM WITHOUT STATCOM

A1 Voltage at Bus B1, B2\& B3

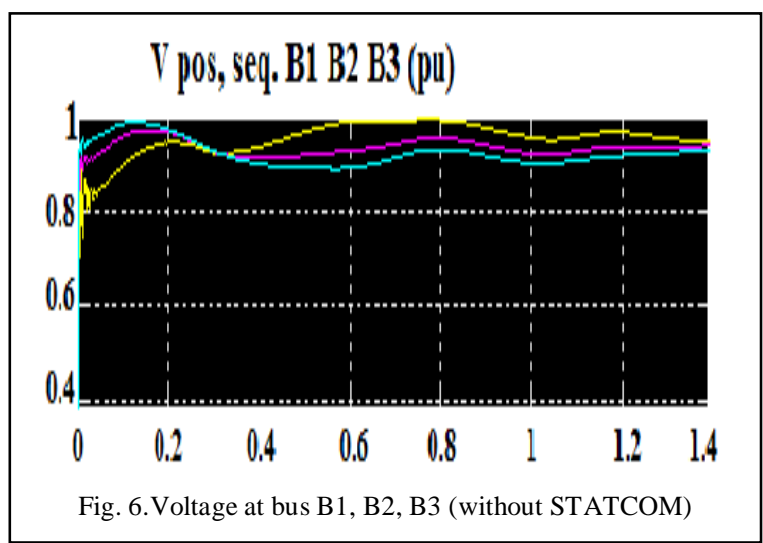

A2. Reactive power without STATCOM

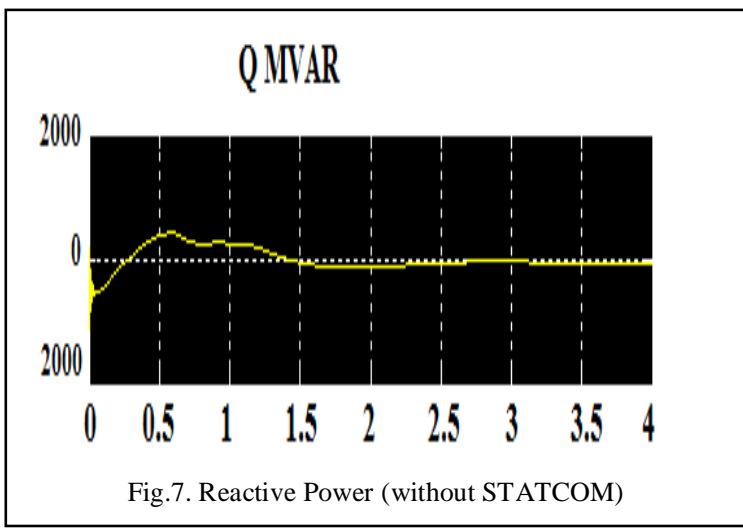

B. WAVEFORM WITH STATCOM

B1 Voltage at Bus B1, B2, B3

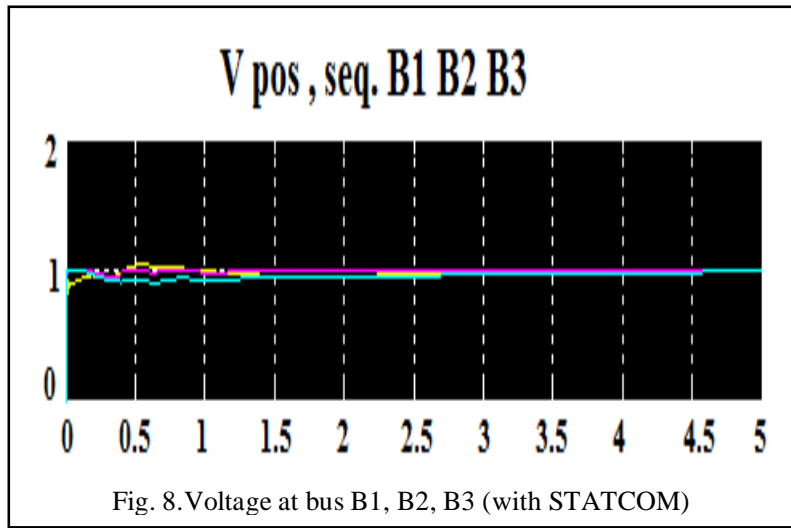

B2. Reactive Power with STATCOM

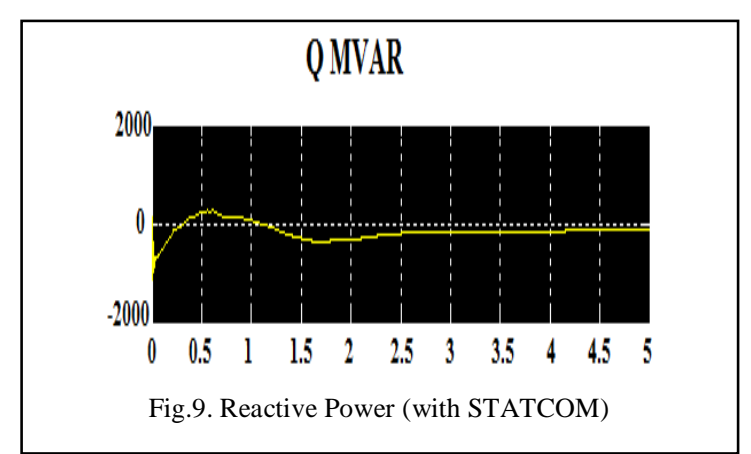


INTERNATIONAL JOURNAL OF INNOVATIVE RESEARCH IN ELECTRICAL, ELECTRONICS, INSTRUMENTATION AND CONTROL ENGINEERING Vol. 2, Issue 12, December 2014

\section{Voltage at buses B1, B2\&B3}

\begin{tabular}{|c|c|c|c|c|c|c|}
\cline { 2 - 7 } & \multicolumn{2}{|c|}{ Voltage at bus } & \multicolumn{2}{c|}{ Voltage at bus 2} & \multicolumn{2}{c|}{ Voltage at bus 3} \\
\hline $\begin{array}{c}\text { TIME } \\
\text { (SEC) }\end{array}$ & $\begin{array}{c}\text { without } \\
\text { STATCOM }\end{array}$ & $\begin{array}{c}\text { With } \\
\text { STATCOM }\end{array}$ & $\begin{array}{c}\text { Without } \\
\text { STATCOM }\end{array}$ & $\begin{array}{c}\text { With } \\
\text { STATCOM }\end{array}$ & $\begin{array}{c}\text { Without } \\
\text { STATCOM }\end{array}$ & $\begin{array}{c}\text { With } \\
\text { STATCOM }\end{array}$ \\
\hline 0.5 & $\mathbf{0 . 9 6 7}$ & $\mathbf{1 . 0 2 0}$ & $\mathbf{0 . 9 2 0}$ & $\mathbf{0 . 9 9 0}$ & $\mathbf{0 . 8 9 1}$ & $\mathbf{0 . 9 1 0}$ \\
\hline 1.0 & $\mathbf{0 . 9 5 6}$ & $\mathbf{0 . 9 8 5}$ & $\mathbf{0 . 9 2 3}$ & $\mathbf{0 . 9 7 4}$ & $\mathbf{0 . 9 0 2}$ & $\mathbf{0 . 9 1 5}$ \\
\hline 1.5 & $\mathbf{0 . 9 3 5}$ & $\mathbf{0 . 9 4 0}$ & $\mathbf{0 . 9 3 7}$ & $\mathbf{0 . 9 7 7}$ & $\mathbf{0 . 9 3 3}$ & $\mathbf{0 . 9 4 0}$ \\
\hline 2.0 & $\mathbf{0 . 9 2 5}$ & $\mathbf{0 . 9 4 2}$ & $\mathbf{0 . 9 3 6}$ & $\mathbf{0 . 9 7 8}$ & $\mathbf{0 . 9 4 0}$ & $\mathbf{0 . 9 4 7}$ \\
\hline 2.5 & $\mathbf{0 . 9 4 2}$ & $\mathbf{0 . 9 6 0}$ & $\mathbf{0 . 9 4 7}$ & $\mathbf{0 . 9 8 2}$ & $\mathbf{0 . 9 4 4}$ & $\mathbf{0 . 9 4 8}$ \\
\hline 3.0 & $\mathbf{0 . 9 5 2}$ & $\mathbf{0 . 9 6 3}$ & $\mathbf{0 . 9 5 3}$ & $\mathbf{0 . 9 8 5}$ & $\mathbf{0 . 9 4 8}$ & $\mathbf{0 . 9 5 6}$ \\
\hline 3.5 & $\mathbf{0 . 9 5 7}$ & $\mathbf{0 . 9 6 6}$ & $\mathbf{0 . 9 5 9}$ & $\mathbf{0 . 9 8 7}$ & $\mathbf{0 . 9 5 6}$ & $\mathbf{0 . 9 6 2}$ \\
\hline 4.0 & $\mathbf{0 . 9 6 3}$ & $\mathbf{0 . 9 7 5}$ & $\mathbf{0 . 9 6 6}$ & $\mathbf{0 . 9 3 3}$ & $\mathbf{0 . 9 6 3}$ & $\mathbf{0 . 9 6 8}$ \\
\hline
\end{tabular}

\section{CONCLUSIONS}

Form the above discussion we can conclude that the reactive power management at receiving end can be produced using STATCOM. By using STATCOM device, the change in voltage profile at smaller limits can be obtained. It can also conclude that a by using STATCOM device we can increase system voltage performance both for high load conditions and small load conditions.

In future we can place STATCOM at maximum voltage location to improve the system permanence. The STATCOM play an important role in controlling the reactive power flow to the power network and hence control both the system voltage variations and transient stability. Also improve the voltage at the time of faults like LG, LL, LLG, LLL faults.

\section{REFERENCES}

[1] N. Yorino, E. E. El-Araby, H. Sasaki, and H. Sugihara, "A new formulation for FACTS allocation for security enhancement against voltage collapse, " IEEE Trans. on Power Syst., vol. 18, no. 1, pp. 3-10, Feb. 2003

[2] Optimal Location of STATCOM and SVC Based on Contingency Voltage Stability by Using Continuation Power Flow: Case Studies of Khouzestan Power Networks in Iran.

[3] Hingorani, N.G."Flexible AC Transmission", IEEE Spectrum, Vol.30, pp.40-45, April 1993

[4] D M TAGARE, "Reactive power management".

[5] Lof P: A et al, Voltage dependent reactive power limit for voltage stability studies, IEEE Transactions on power system. Vol .10, No. 1, Feb 1995 , pp. 220-226 